\title{
Educação Escolar Quilombola em Escola Urbana: (Des)Conhecimento dos valores civilizatórios de um povo
}

\section{Quilombola School Education in an Urban School: (Un)knowledge of the civilizing values of a people}

\section{La educación Escolar Quilombola en una Escuela Urbana: (Falta de)conocimiento de los valores civilizadores de un pueblo}

Maria de Fátima Garcia ${ }^{1}$

Ana Maria Pereira Aires ${ }^{2}$

Janaína Jardiny Dantas de Araújo ${ }^{3}$

1. Graduação em Letras. Doutorado em Educação. UFRN. maria defatima@yahoo.com.br

2. Graduação em Pedagogia Doutorado em Educação. UFERSA. ana.aires@ufersa.edu.br

3. Graduação em Pedagogia. EE D. José Adelino Dantas. janainajardiny@ gmail.com.br

RESUMO: Este estudo analisa as práticas escolares de uma Escola Municipal situada em região urbana do Seridó Potiguar do estado do Rio Grande do Norte, sob a ótica dos valores civilizatórios de uma comunidade quilombola, geograficamente localizada no município de Currais Novos, RN. O Estudo, de abordagem qualitativa, pautou-se em entrevistas com pais de estudantes quilombolas e aplicação de questionários a professores da escola que atuam com alunos quilombolas. Fundamentado nas ideias de Santos (2010) e Quijano (2010) no que se refere aos conceitos de pensamento abissal, eurocentrismo, colonialismo e colonialidade; e no diálogo com as ideias de estudiosos da temática africana (Kilomba, 2008), conclui-se que, tanto na visão dos pais, quanto na empiria levantada junto aos professores, as práticas escolares não contemplam os marcos legais das políticas de ações afirmativas e desconsideram os valores e dinâmica civilizatória afrobrasileira, indicando a necessidade de formação dos professores para descolonização do currículo.

Palavras-chave: Educação Escolar Quilombola; Comunidade Remanescente de Quilombolas; Alunos Quilombolas; Práticas Escolares; Valores Civilizatórios.

\begin{abstract}
This study analyzes the school practices of a Municipal School located in the urban region of Serido Potiguar in the state of Rio Grande do Norte, from the perspective of the civilizing values of a quilombola community, geographically located in the municipality of Currais Novos, RN. The study, with a qualitative approach, was based on interviews with parents of quilombola students and the application of questionnaires to school teachers who work with quilombola students. Based on the ideas of Santos (2010) and Quijano (2010) regarding the concepts of abyssal thinking, eurocentrism, colonialism and coloniality; and in the dialogue with the ideas of scholars of African and Afro-Brazilian themes, it is concluded that, both in the parents' view, as in the empiricism raised with the teachers, school practices do not contemplate the legal frameworks of affirmative action policies and disregard Afro-Brazilian civilizing values and dynamics, indicating the need for teacher training for the decolonization of the curriculum.
\end{abstract}

Keywords: Quilombola School Education; Remnant Community of Quilombolas; Quilombo students; School Practices; Civilizing Values.
RESUMEN: Este estudio analiza las prácticas escolares de una Escuela Municipal ubicada en la región urbana de Seridó Potiguar en el estado de Rio Grande do Norte, desde la perspectiva de los valores civilizadores de una comunidad quilombola, ubicada geográficamente en el municipio de Currais Novos, RN. El estudio, con un enfoque cualitativo, se basó en entrevistas a padres de alumnos quilombolas y la aplicación de cuestionarios a profesores de escuela que trabajan con alumnos quilombolas. Basado en las ideas de Santos (2010) y Quijano (2010) sobre los conceptos de pensamiento abismal, eurocentrismo, colonialismo y colonialidad; y en el diálogo con las ideas de estudiosos de temas africanos y afrobrasileños, se concluye que, tanto en la visión de los padres, como en el empirismo planteado con los docentes, las prácticas escolares no contemplan los marcos legales de las políticas de acción afirmativa. y desconocer los valores y dinámicas civilizatorias afrobrasileñas, lo que indica la necesidad de formación docente para descolonizar el currículo.

Palabras-clave: Educación Escolar Quilombola; Comunidad remanente de quilombolas; Estudiantes quilombolas; Prácticas escolares; Valores Civilizatórios.

Recebido em: 15/06/2021

Aprovado em: 12/10/2021

Todo o conteúdo deste periódico está licenciado com uma licença Creative Commons (CC BY-NC-ND 4.0 Internacional), exceto onde está indicado o contrário. 


\section{INTRODUÇÃO}

Este estudo é um extrato, sob a forma de pesquisa, de um programa de extensão, intitulado PróQuilombola: Negros do Riacho, Comunidade e Universidade Juntos (PROEXT, anos 2016-2017) no âmbito da dimensão que associa pesquisa e extensão. Um dos objetivos do referido Programa consistia em promover a formação integral dos estudantes de graduação envolvidos em temáticas relacionadas às questões étnico-raciais e promotoras da igualdade racial nos diferentes contextos de atuação profissional e produção de conhecimentos. As ações tiveram como cenário a comunidade quilombola Negros do Riacho, situada na cidade de Currais Novos, estado do Rio Grande do Norte/Brasil, lugar onde foram desenvolvidas ações articuladas com as especificidades locais e históricas, características de comunidades remanescentes tais como: Memória coletiva, saberes tradicionais, territorialidade, valores civilizatórios e patrimônio cultural. Ações se deram também no âmbito da formação continuada de professores da escola quilombola local, orientados sob os princípios da educação escolar quilombola, especificamente, em seu currículo e na construção de um projeto pedagógico diferenciado (AIRES; GARCIA, 2020; AIRES; LEITE, 2018) ao mesmo tempo em que se conhecia melhor as vivências, interações e a cultura no cotidiano da própria comunidade (GARCIA; DANTAS, 2018). Por outro lado, no decorrer das atividades do Programa, percebeu-se a necessidade de investigar como se desenvolvia a educação de meninos e meninas quilombolas em outro espaço, o da escola urbana, fora da comunidade, que atende estudantes oriundos de territórios quilombolas para onde se dirigiam os e as adolescentes a partir do sexto ano de escolaridade. Essa escola, aqui identificada como P.H.G distancia-se da comunidade em torno de $12 \mathrm{~km}$, pois, nem sempre as comunidades quilombolas possuem escolas ou, no caso desta [comunidade], a escola mais próxima oferecia apenas a educação infantil e os anos iniciais do ensino fundamental, fator este

que leva crianças, jovens e adultos quilombolas serem transportados para fora de suas comunidades de origem. Observa-se que as unidades educacionais estão longe das residências, o acesso é difícil, os meios de transporte são insuficientes e inadequados, e o currículo das escolas localizadas fora da comunidade muitas vezes está longe da realidade histórica e cultural destes alunos e alunas (BRASIL).

Assim, motivadas pela curiosidade epistêmica relacionada à implementação das Diretrizes da Educação Escolar Quilombola no que se refere aos princípios que a regem, o estudo buscou ouvir e analisar, com base nas entrevistas feitas aos pais e mães (identificados neste texto como Pais/Mães), e respostas ao questionário dirigido aos professores (Prof. 1, 2, 3,4) responder à seguinte indagação: "Na visão dos pais de alunos quilombolas, as práticas escolares da Escola Municipal P.H.G. têm contribuído para a valorização da identidade, tradições e costumes da Comunidade Quilombola Negros do Riacho?"

Barros (2009) em sua obra "A Construção Social da Cor", alerta para o fato de que em torno da percepção social daquelas pequenas diferenças que se expressam no nível biológico sob a forma de distintas tonalidades da pele humana, existem centenas de anos de história a serem considerados. Essa afirmação sai da teoria e entra na dimensão concreta quando se conhece a comunidade quilombola "Negros do Riacho". As pessoas que ali vivem têm sua ancestralidade comum originária na diáspora africana, na população afroescravizada pelos colonizadores portugueses, pretensamente libertados por uma lei que em nada lhes favoreceu, pelo contrário, os atou em uma corrente hegemônica de pobreza e miséria. Favelização, exclusão educacional, morte, políticas excludentes, racismo, preconceito, constituíram-se em evidências da vulnerabilidade a que esses grupos se encontram expostos. Hoje, com a mundialização do capital, o processo colonizador comandado pela Europa nórdica sobre os países abaixo da linha do Equador durante os séculos XIV ao XX deram origem ao que alguns autores (QUIJANO; SANTOS, 2010; KILOMBA, 2008), têm denominado de colonialidade do poder. Colonialidade implica hierarquização do poder, latente nas dimensões políticas, econômicas, sociais, culturais e simbólicas. Os códigos da cultura dominante 
reverberados pelos artefatos informacionais (mídias e ferramentas de veiculação da comunicação) e patrocinados pelo capital econômico, subalternizam as culturas e continentes anteriormente colonizados. Tudo o que não é hegemônico em relação ao capital encontra-se, não apenas alijado, mas, inferiorizado. Dessa forma, há que se pensar a educação, o currículo da escola quilombola, a saúde e o desenvolvimento local voltados ao fortalecimento da comunidade, numa concepção decolonialista.

O caminho teórico-metodológico trilhado teve como abordagem a pesquisa qualitativa por esta ter como cenário o ambiente natural como sua fonte direta de dados (LUDKE; ANDRÉ, 2003). A revisão da literatura serviu de suporte para o conhecimento da história de vida dos negros nos quilombos, da comunidade quilombola Negros do Riacho bem como para subsidiar a empiria obtida durante todo o percurso de elaboração do trabalho, em diálogo com autores como: Santos (2010), Quijano (2010); Almeida (2019) e Nascimento (2019) (bem como outros estudiosos da temática africana e afro-brasileira possibilitadores da compreensão do objeto estudado pelo viés dos conceitos de Pensamento Abissal, Eurocentrismo, Colonialismo e Colonialidade, os quais são estruturantes deste trabalho em diálogo com os marcos legais que oferecem a estrutura para se operacionalizar a educação escolar quilombola: A Lei 10.639/03, que alterou a Lei de Diretrizes e Bases da Educação Nacional 9394/96, e a Resolução no No 8 , de 20 de Novembro de 2012 que define as Diretrizes Curriculares Nacionais para a Educação Escolar Quilombola na Educação Básica.

Também fizeram parte da metodologia da pesquisa procedimentos de observação in lócus na comunidade quilombola Negros do Riacho com vistas ao conhecimento do espaço, entrevistas com pais/mães dos alunos da comunidade que estudam na Escola Municipal P.H.G. para perceber como estes avaliam o trabalho da instituição em relação a história, cultura e valores inscritos na existência dessa população. As entrevistas foram realizadas com sete pais/mães de quinze alunos que estudavam no Ensino Fundamental Séries Finais ( $6^{\circ}$ ao $9^{\circ}$ ano), turno vespertino, na Escola Municipal P.H.G. O desenvolvimento da entrevista deu-se em dois dias, de modo que a cada visita também eram feitas as observações no espaço da comunidade. Como subsídio, ou em busca de pontos em comum, semelhanças e diferenças nos discursos, foram aplicados questionários aos professores que lecionam aos alunos provenientes da comunidade, em busca de conhecer como são realizadas suas práticas e constatar como tem sido operacionalizada da lei 10.639/03 que institui a obrigatoriedade do ensino da História e Cultura Afro-Brasileira e Africana nas instituições escolares brasileiras. Optou-se pelo questionário por ser "um instrumento de coleta de dados constituído por uma série ordenada de perguntas que devem ser respondidas por escrito pelo informante, sem a presença do pesquisador" (GERHARDT; SILVEIRA, 2009, p.69).

Para aplicação dos questionários foram feitas duas visitas à escola, no mês de abril de 2017, obtendose três questionários respondidos, de um total de seis professores, o que equivale a um quantitativo de $50 \%$ dos professores, sujeitos da pesquisa.

Tanto a entrevista quanto o questionário tiveram como suporte os documentos legais: A Lei 10.639/03 e as Diretrizes Curriculares Nacionais para a Educação Escolar Quilombola. Os instrumentos da pesquisa continham várias perguntas para que se chegasse à seleção de respostas indispensáveis ao estudo, assim, houveram perguntas/respostas que não foram contempladas nas análises.

\section{A Diáspora Africana Escravizada e a Consequente Formação dos Quilombos}

Santos (2008) ajuda a entender o significado de diáspora ao afirmar que:

Desde a década de 1990, no bojo das discussões sobre globalização, nacionalismo, identidade e multiculturalismo, o termo diáspora vem sendo utilizado como projeto político e acadêmico que questiona as ideias de pureza racial, identidade, território e cultura nacional. A perspectiva de estudo passa a ser balizada na redefinição crítica do lugar da África, dos africanos e seus descendentes na formação do Ocidente, o que exige um grande esforço teórico para abranger as mais diversas experiências das populações negras dispersas em escala mundial (SANTOS, p. 185, 2008). 
Falar de remanescentes de quilombos implica retroceder na história de formação do Brasil e nela identificar a chegada dos colonizadores portugueses que, por sua vez, também haviam recém chegado ao continente africano com o mesmo intuito: a colonização e expansão de seus territórios. Paul Gilroy (apud SANTOS, 2008) elabora a noção de diáspora "como um processo dinâmico, multifacetado, o qual rompe com aquelas ideias cristalizadas que tomam a diáspora africana como um fenômeno preso ao passado". Estando os colonizadores neste e também do outro lado do Oceano Atlântico, certamente, lhes facilitou o sequestro e a escravização da população africana para as Américas dando início e manutenção à diáspora africana por trezentos anos sob o prisma da barbárie. Gilroy cria a metáfora Atlântico Negro (grifo das autoras)

para entender a estrutura transnacional criada na modernidade e que deu origem ao sistema de comunicações globais definido pelo ir e vir de pessoas, informações e mercadorias que redefiniram novos padrões e trocas culturais [...] O Atlântico e a vida marítima [...]nos sugerem deslocamentos, movimentos no meio líquido e misturas que extrapolam a noção de raça, desterritorializam a cultura e nos indicam um circuito comunicativo que modifica e transcende as fronteiras étnicas e nacionais. (GILROY apud SANTOS, p. 185-208).

A essa forma de compreensão dos deslocamentos forçados do continente africano para outros continentes coloca-se o desafio de revisitar a História (e Geografias) das Américas sob outros prismas para nelas perceber que houveram muitas lutas e resistências, pois, "se estivermos conscientes dos níveis insuportáveis de barbarismo associados à escravidão no Novo Mundo, torna-se fácil entender a importância dos quilombos" (REIS; GOMES, 1996, p. 27-28). Ou, mesmo, entender qual/is lugar(es) o colonialismo e, atualmente, a colonialidade reservam aos afro-diaspóricos, quer seja na escola, no trabalho, na sociedade como um todo, pois, nos afirma Santos (2010) em relação à ideologia da colonização, "o colonial é o estado de natureza onde as instituições da sociedade civil não têm lugar. Hobbes refere-se explicitamente aos “povos selvagens em muitos lugares da América” (SANTOS, 2010, p. 36). No Brasil, em meados do século XVI, as ideologias de colonialismo, escravidão, primitivismo e capitalismo associavam-se à necessidade dos portugueses em obter lucro na nova colônia recém achada.

A escravidão pode ser definida como um processo que transforma o ser humano em propriedade, impedindo-o de realizar suas vontades e tornando-o sujeito à autoridade e domínio de outrem. Inicialmente, a atividade principal foi a produção de açúcar nos engenhos que fez dos indígenas nativos sua força de trabalho forçado. No entanto, a escravização indígena foi dando lugar ao comércio de negros africanos para o trabalho escravo nas casas de engenho, aos quais eram atribuídas diversas funções: Na agroindústria canavieira, na agricultura cafeeira, na atividade aurífera e nas atividades domésticas, variando o dia-a-dia dos escravos de acordo com a tarefa que exerciam. E foi assim que teve início o enorme comércio que arrancou milhares de africanos de suas terras, alterando profundamente a configuração do continente africano em termos demográficos, econômicos, sociocultural e político.

Entender essa dinâmica escravocrata nos remete a Santos (2010) em relação ao conceito de Cartografia Abissal por apontar que enquanto uma parcela da população humana se firma e afirma-se como humano, a outra é negada e se sacrifica para que a primeira tenha vida plena: "A negação de uma parte da humanidade é sacrificial, na medida em que constitui a condição [de existência] para a outra parte" (SANTOS, 2010, p. 36). Também, a cartografia abissal se evidencia quando Santos (2010), nos alerta que:

O colonial, constitui o grau zero a partir do qual são construídas as modernas concepções de conhecimento e direito. As teorias do contrato social dos séculos XVII e XVIII são tão importantes pelo que dizem tanto pelo que silenciam. O que dizem é que os indivíduos modernos, ou seja, homens metropolitanos, entram no contrato social abandonando o estado de natureza para formarem a sociedade civil. (SANTOS, 2010, p. 36). 
No entanto, o povo negro sempre resistiu à colonização e ao domínio de seus corpos e força de trabalho e, organizados através de revoltas e ou fugas individuais ou coletivas, davam corpo a uma nova sociedade - os quilombos - cuja organização liberta do poder escravocrata, abarcava não somente escravizados, mas outros grupos vulneráveis que estavam em situação de opressão ou aqueles que, simplesmente, buscavam um refúgio. Assim, estes espaços se constituíam em uma sociedade multiétnica de povos que traziam suas contribuições culturais e somavam às dos seus companheiros dando forma ao que hoje, graças a Abdias Nascimento, se denomina Quilombismo, conceito em construção científicohistórica, mas também aquilombamento, referindo-se às comunidades e grupos que militam, produzem políticas públicas, lutam e se defendem da estrutura racista incorporadas nas práticas e mentalidade brasileira.

\section{Sobre Quilombismo e Aquilombamentos}

Os antigos quilombos, dos quais o mais conhecido é o de Palmares, conseguiram manter-se preservados mesmo após a abolição da escravatura em espaços que hoje denominam-se como Comunidades Remanescentes de Quilombolas. São nesses locais de resistência em que descendentes de escravos se aquilombam e buscam conservar as tradições, os costumes e as religiosidades na incessante busca de construir e ressignificar sua identidade.

As lutas travadas desde o início da escravidão, foram lentamente conseguindo conquistas para esses povos. Cem anos após a abolição da escravatura foi elaborada e publicada a Constituição Federal de 1988, sendo o primeiro documento legal que reconheceu o direito à propriedade da terra às comunidades quilombolas. Em seu art. 68 do Ato das Disposições Transitórias consta: "Aos remanescentes das comunidades dos quilombos que estejam ocupando suas terras é reconhecida a propriedade definitiva, devendo o Estado emitir-lhes os títulos respectivos" (BRASIL, 1988).

$\mathrm{O}$ direito à terra e o reconhecimento como remanescente de quilombolas apresentou importante avanço nas lutas travadas por este povo desde a abolição da escravatura. Grande significância agrega a terra para os quilombolas, pois ela não tem o mesmo valor que possui para os grandes proprietários, ela é, antes de tudo, uma forma de sustento, resgate e preservação da memória dos antepassados, é o espaço social onde revivem tradições, preservam seus valores civilizatórios e lutam para garantir o direito à igualdade. Terra para os quilombolas significa território porque sabem que mesmo com todos os direitos em lei, são inúmeras as formas de exclusão enfrentadas social e juridicamente. Enquanto a lei reconhece, a sociedade segrega e os discrimina em todos os ambientes e diversas circunstâncias interferem na valorização da identidade negra e quilombola, na perpetuação das tradições ancestrais e na manutenção dos valores civilizatórios ancestrais. .Por isso, cabe à escola ter conhecimento de que

A história dos quilombos não se limita à resistência à escravidão. Ela está imersa nos processos de resistência ao padrão de poder, apropriação, expropriação da terra, imposto aos africanos escravizados e a seus descendentes. Os povos quilombolas têm a consciência dessa relação persistente entre sua história e as lutas pela manutenção de seus territórios. (PARECER CNE/CEB Nº16/2012, p. 14).

Estes fatores fazem com que o diferente vá se perdendo, sendo desvalorizado e ignorado, impulsionando cada vez mais novas lutas das instituições sociais e das comunidades que em seu seio devem fortalecer a união e buscar modos de valorizar e perpetuar seus costumes, tradições e culturas.

Abdias Nascimento (1914-2011) nos lembra que o quilombo de Palmares reuniu uma população de, aproximadamente, 30.000 homens e mulheres e estabeleceu o "primeiro governo de africanos livres nas terras do Novo Mundo [...] conhecido na história como República de Palmares" (NASCIMENTO, 2019). 
Após Palmares muitos outros quilombos, outras tantas lutas, centenas de heróis negros invisibilizados pela história do Brasil, tantas vidas foram sacrificadas para se chegar ao Brasil de hoje, que aliás, permanece focado na extinção do povo negro. Abdias Nascimento cria o conceito de quilombismo e o verbo aquilombar. Para esse autor, quilombo não deve guardar o significado de negro fugido, mas sim, o de reunião, comunidade fraternal e libertação. Quilombo é uma sociedade e deve ser vista como uma etapa no progresso humano, social e político. Quilombo é comunitarismo e igualitarismo econômico. Com base nisso, Nascimento conclama a geração atual de negros e negras a "edificar a ciência histórico-humanista do quilombismo" (idem; grifo das autoras), fundamentados pelo patrimônio legado pelos quilombos dos séculos XV, XVI, XVII, XVIII e XIX. Ou seja, o quilombismo deve se erigir sobre um "método de análise, compreensão e definição de uma experiência concreta. [...] expressa a ciência do sangue escravo, do suor que este derramou enquanto pés e mãos edificadores da economia deste país. Um futuro de melhor qualidade para a população brasileira [...] assegurar a condição humana do povo afro-brasileiro [...] é o fundamento ético do quilombismo" (NASCIMENTO, 2019).

Aquilombamento significa reunir-se em 'atitude de quilombo', aconchegar-se, protegerem-se mutuamente, entender os contornos e vencer juntos os desafios de uma sociedade (cotidianamente) racista. Sociedade esta presente nas instituições públicas e privadas, dentre elas, a Escola. Foi graças ao aquilombamento que as populações, habitantes (dentro e fora) dos quilombos, perceberam que outra via era possível à libertação social, histórica, política, econômica e também, educacional, pois, os negros sempre educaram, por meio do ensino da leitura e da escrita a seus irmãos que não as dominavam. O direito de existir e de resistir está intrinsicamente amalgamado tanto ao quilombismo enquanto ciência quanto ao movimento e ato de aquilombar-se.

\section{A Comunidade Quilombola Negros do Riacho}

A Comunidade Quilombola Negros do Riacho está localizada a $12 \mathrm{~km}$ da cidade de Currais Novos/RN e teve sua certificação conquistada como comunidade quilombola emitida em maio de 2006 pela Fundação Cultural Palmares.

$\mathrm{Na}$ história oral três versões abordam o surgimento da comunidade, no entanto, qualquer que seja a forma de se narrar, a história tem seu ponto inicial com um ancestral negro de nome Trajano Lopes da Silva, também chamado de "Trajano Passarinho", "Trajano Velho" ou "Trajano Preto". Na memória, Trajano é tido como o falecido que marca as memórias da fundação daquele lugar, o dono do Riacho, que legou aquelas terras para uso comum de seus descendentes, as quais tiveram sua apropriação alimentada e reafirmada pelo uso cotidiano do espaço, como forma de manutenção da vida. Todavia, não foram encontrados documentos formais que evidenciassem como Trajano Passarinho adquiriu as terras na povoação Currais novos.

Na comunidade há duas lembranças que dialogam quando se trata dos tempos idos: A primeira tem relação com a seca, a fome, as necessidades familiares e a prática de mendicância. Já a segunda se remete ao catolicismo e às grandes festividades em honra a São João e São Sebastião, santo padroeiro da comunidade. Muitas tradições foram perdidas, mas ainda uma das que se mantém preservada notabiliza a fabricação da cerâmica, porém, de forma reduzida a apenas duas mulheres que praticam a venda de seus produtos em feiras da cidade de Currais Novos/RN. A oura refere-se à festa de honra ao padroeiro São Sebastião que acontece no mês de janeiro, com leilão, novenas e festejos com bandas de música. Também, vale mencionar os festejos juninos (mês de junho) que se iluminam pelas fogueiras distribuídas na comunidade.

De acordo com os registros levantados para fins do programa de extensão ao qual esta pesquisa estava associada, a comunidade possuía no ano de 2017, aproximadamente 60 famílias, distribuídas em casas de alvenaria advindos dos programas sociais, algumas distantes e outras bem próximas, formando uma espécie de centralidade. As casas de "taipa" que antes constituíam a maioria da comunidade, à época, resumiam-se somente a duas. Ao seguir o percurso de casas rumo ao "centro" da comunidade encontram- 
se pelo caminho alguns poucos animais (porcos, galinhas e bodes), bem como visualizam-se moradores, em sua maioria crianças, que se debruçam nas janelas e portas de suas casas para observar a chegada dos "estranhos" em seu território. Podemos encontrar também, raros moradores que ainda utilizam a prática da mendicância, pedintes de esmolas a todos os motoristas que chegam à comunidade.

O contato inicial com os moradores, por vezes é dificultado, pois há neles o estranhamento para com os que vêm de fora para seu espaço, havendo razão para isso: As pessoas que lá chegam, demonstram uma espécie de curiosidade em relação "aos quilombolas", como se fossem algo exótico, aproximado à natureza, ao primitivismo. Grada Kilomba (2008) destaca em sua obra Memórias da Plantação, o poder exercido pelas fantasias psíquicas do sujeito branco em relação à pessoa negra como sendo esta última, a Outridade (o outro). O diferente é sempre definido racialmente pelo que se vê como branco em relação aos dilemas de repressão e representação mental dessa mesma branquitude, sendo o sujeito negro a negação daquilo que o branco não quer ser, tampouco, parecer, tudo o que lhes causa vergonha é reprojetado nos negros. As fantasias brancas colocam os sujeitos negros

como se estes fossem a tela de projeção daquilo que o sujeito branco teme reconhecer sobre si mesmo, neste caso: a ladra/ão, a/o bandida/o, o/a indolente e maliciosa/o. Tais aspectos desonrosos, cuja intensidade causa extrema ansiedade, culpa e vergonha são projetados para o exterior como um meio de escapar dos mesmos. [...] No mundo conceitual branco o sujeito negro é identificado como a parte "boa" do ego, enquanto as manifestações da parte "má" são projetadas para o exterior e vistas como objetos externos e "ruins" (KILOMBA, p. 37, 2008).

Portanto, a comunidade, de antemão, mantém distante de sua privacidade os visitantes curiosos de sua cultura, assim, a facilitação desse contato vai se dando aos poucos, pelas sucessivas visitas, até que ganhem confiança e entendam o porquê da aproximação, sendo as crianças os primeiros moradores a manter diálogo. A organização familiar na comunidade é bem diversa: pode-se encontrar casas com mais de uma família dividindo o mesmo ambiente, bem como encontrar moradias com apenas um morador. A maioria da comunidade é constituída por crianças, jovens e adultos, sendo difícil encontrar idosos. Atualmente, a maior parte da renda tem origem na produção e comercialização do carvão vegetal, nas aposentadorias, no trabalho ocasional como diaristas em sítios vizinhos, nos programas sociais de assistência do governo, na pequena agricultura e na rara, mas ainda existente, prática de mendicância (Diário de Campo das pesquisadoras).

Nas conversas com moradores é possível perceber que a renda garante o sustento da família, fato que no passado era mais complicado, havendo momentos em que a fome prevaleceu. No momento da pesquisa os programas sociais somavam a maior fonte de renda da comunidade, o que fez com que mesmo com o desemprego das pessoas ainda se considerem como tempos de "fartura", apesar da diminuição das plantações agrícolas acarretada pelas secas. Todos que lá habitam permanecem como herdeiros da terra conquistada por Trajano Passarinho, um lugar onde teceram histórias, construíram ligações de parentesco, projetaram formas de viver partilhando conquistas e dificuldades, sonhos, lutas, construindo-se assim, o espaço no qual residem.

A história da Comunidade Quilombola Negros do Riacho se faz necessária para compreender o trabalho das instituições escolares que atendem as crianças e jovens da comunidade, seja ela instituição rural ou urbana. É relevante que as crianças conheçam, narrem e se identifiquem com a história de sua diáspora, já que são os protagonistas destas, imprescindível ao reconhecimento e a valorização da sua identidade. 


\section{A Escola Urbana que Atende Alunos Oriundos de Territórios Quilombolas: Práticas e dinâmicas (des)valorizatórias do povo remanescente quilombola}

As linhas cartográficas do pensamento ocidental colocam a população num processo de constante subalternização, onde a epistemologia, isto é, o conhecimento validado pela Ciência, define as separações. O grande processo de lutas e enfrentamentos pelo rompimento de ideias e valores que excluíam a história e a participação do povo descendente dos africanos na formação da cultura brasileira resultou no reconhecimento da diversidade étnico racial por meio de políticas de ações afirmativas que obrigam a escola a se adequar às diferentes culturas e aos diferentes indivíduos que agrega em seu seio. A escola se constitui no espaço por excelência de educação formal, e é no processo de escolarização que os diversos sujeitos ali inseridos constroem conhecimentos por meio de representações e valores que podem ser moldados conforme as intencionalidades da instituição, assim, a escola passa a ser também um espaço de priorização de uma cultura e negação de tantas outras ocultadas e subalternizadas.

Subalterno é um nome que designa um atributo geral de subordinação [...] desde que seja expresso em termos de classe, casta, idade, identidade sexual, profissão ou de qualquer outra maneira. Sem dúvida podemos considerar que uma destas "outras maneiras" educadas" é a distinção entre pessoas "educadas" e "não (ou parcialmente) educadas" que conferem o "adoutrinamento", os procedimentos e resultados do saber acadêmico e da alta cultura, tanto em contextos metropolitanos como em contextos coloniais e póscoloniais (RANAJIT GUHA apud BEVERLEY, 2014, p. 35).

Em vista disso, é importante analisar se as práticas adotadas na escola que atende estudantes quilombolas estão atentas aos sofrimentos cotidianos imputados pelo racismo que estrutura a sociedade brasileira (ALMEIDA, 2019), ao evidente cerceio aos direitos e apagamento de seus valores civilizatórios. Somente ao considerar esse histórico em suas práticas é que a instituição será capaz de educar buscando valorizar a grande contribuição do povo negro na sociedade brasileira e sair do reducionismo e imagem representacional de povo escravizado.

De acordo com o Artigo $1^{\circ}, \S 1^{\circ}$ da Resolução n. 8/2012, definidora das Diretrizes Curriculares Nacionais para a Educação Escolar Quilombola na Educação Básica os princípios que a regem orientam a organizar o ensino ministrado na escola fundamentando-se, informando-se e alimentando-se:

a) da memória coletiva; b) das línguas reminiscentes; c) dos marcos civilizatórios; d) das práticas culturais; e) das tecnologias e formas de produção do trabalho; f) dos acervos e repertórios orais; g) dos festejos, usos, tradições e demais elementos que conformam o patrimônio cultural das comunidades quilombolas de todo o país; $\mathrm{h}$ ) da territorialidade (BRASIL, 2013, p. 479).

Assim, ao optar pela Escola Municipal P.H.G enquanto lócus para pesquisa levou-se em consideração o fato de que a maioria das crianças que saem do Ensino Fundamental I cursado na Escola Rural Multisseriada São Francisco de Assis, em um sítio distante dois quilômetros da comunidade, vão para a cidade (distante 12 quilômetros) cursar o Ensino Fundamental II. Fazia-se imprescindível buscar informações sobre o trabalho da escola com vistas a conhecer suas práticas escolares e analisar os avanços ocorridos após as legislações e as intensas lutas antirracistas que se instalam hoje no contexto da sociedade brasileira, relembrando que, neste estudo, busca-se investigar a visão dos pais e mães sobre a educação que seus filhos recebem na escola urbana. Essa escola reconhece, valoriza e afirma os direitos do povo negro quilombola suas lutas e resistências? Procurou-se obter a resposta sob duas óticas: a dos próprios pais e a dos professores. Em relação a estes últimos, questionando-os sobre o conhecimento da Lei 10.639/03 que, como mencionado anteriormente, institui a obrigatoriedade do ensino da História e Cultura Afro-Brasileira 
nos estabelecimentos de ensino. A este questionamento todos foram unânimes ao responder que sabiam da existência da Lei, no entanto, não tinham aprofundamento nela.

Dessa maneira começava-se a evidenciar que se os professores apenas 'sabem' que existe a lei e, por aprofundamento entende-se a operacionalização da mesma, começam a surgir evidências de que, devido ao desconhecimento operacional da 10.639/03, as práticas pedagógicas voltadas às questões étnico-raciais já se fragilizassem, o que se comprovou no decorrer da pesquisa quando demonstraram não ter conhecimento também das Diretrizes Curriculares Nacionais para a Educação Escolar Quilombola.

Em relação à valorização da comunidade e construção da identidade negra quilombola quando questionados sobre as práticas pedagógicas adotadas em sala para valorizar a comunidade e os alunos dela oriundos, os professores se posicionaram:

Prof. 1: A gente adota que eles se reconheçam. Você já foi na comunidade? Eles não gostam de estudar. Pra eles o $9^{\circ}$ ano é o fim dos estudos, não tem perspectiva, depois do $9^{\circ}$ ano se casa, tem filhos e pronto.(Sic).

Prof. 2: Trabalho a autoestima deles, quando valorizo, engrandecendo.(Sic).

Percebe-se nestas afirmações a contradição entre o trabalho pelo reconhecimento e ao mesmo tempo a desvalorização dos estudantes, vistos como aqueles que "não gostam de estudar", "não têm perspectiva", e o determinismo social "depois do $9^{\circ}$ ano, casa, tem filhos e pronto". A palavra "pronto" soa como uma sentença de finitude. Mas, pergunta-se, - O que a escola faz mostrar as múltiplas perspectivas de vida para esses estudantes?

A questão da valorização da comunidade se torna explícita no momento em que perguntamos aos pais/mães se eles acham que a escola valoriza as tradições da comunidade e como eles percebem isso junto a seus filhos, obtendo-se como respostas:

Pai/Mãe 1: Não, porque as meninas nunca chegam dizendo nada. (Sic).

Pai/Mãe 2: Não, porque não tem contato, não tem como saber as tradições. (Sic).

Pai/Mãe 3: Valoriza, hoje tem escola e carro. (Sic).

Pai/Mãe 4: Valoriza, não chega discriminando aqui não (Sic).

Nessas falas evidencia-se que se a escola não se aproxima da comunidade não há como ter conhecimento dos valores e tradições e também porque, caso houvesse, as crianças trariam essa informação em conversas informais sobre o ensino recebido na escola. Sem conhecimento da história da comunidade não há como alimentar o currículo escolar e assim propiciar que os estudantes quilombolas se vejam nele representados. Ademais, mesmo quando dizem que essa valorização acontece os pais e mães confundem valorização com cumprimento dos direitos garantidos em lei, aqui expressos na forma de transporte escolar dos alunos da comunidade até a escola ou, ainda, entendem valorização como sinônimo de não discriminação.

O pouco contato com os pais e demais pessoas da comunidade é enfatizado pelos professores como algo que ocorre apenas em comemorações. Ao serem indagados acerca de como se dá a participação dos pais e pessoas da comunidade na escola, e como acontece a relação entre professores, pais e mães, obtivemos como respostas:

Prof. 1: Os pais só vão quando tem algo em troca, quando eles sabem que tem comida vão. (Sic).

Prof. 2: A escola que vai à eles, geralmente o contato é nas comemorações. (Sic).

O contato ocorrido em comemorações não oferece oportunidade para que se discuta individualmente com os pais acerca do desenvolvimento de seus filhos, tampouco, sobre aspectos importantes da própria comunidade que poderiam compor projetos de ensino que envolvessem os estudantes, seus pais e demais 
pessoas da comunidade. Por outro lado, o professor a seguir narrou uma prática que até poderia ser aproximativa à identidade e valores da comunidade Negros do Riacho, porém, escondida nas palavras, percebe-se a exclusão: "Aí, pra não deixar eles de fora, fomos na comunidade", demonstra que o acesso ao direito a um currículo escolar que os represente ainda não fazia parte da política da escola em estudo:

Prof. 3: Olhe a gente fez um projeto aqui sobre patrimônio material e imaterial, fomos até pra Natal apresentar lá. A gente fez esse projeto trabalhando as ruas de

Currais Novos uma por uma. Aí, pra não deixar eles de fora, fomos na comunidade. Você já foi lá? Ainda tem aquelas pedras? Porque eles marcaram com pedras as ruas da comunidade. Tem umas árvores lá que foi até nós que plantamos (Sic).

Conforme as respostas podemos perceber que as práticas de valorização são resumidas ao simples fato de trabalhar o reconhecimento, todavia, cabe saber como é representada a imagem de quilombolas. Se o trabalho se faz através de uma imagem depreciativa, subalternizando, certamente o auto reconhecimento da identidade ficará comprometido. Ao julgar os alunos conforme o nível de escolarização e mencionar que eles "não gostam de estudar", o professor 1 recai justamente na prática que há pouco mencionada, ele inferioriza, rotula e ainda busca que seus alunos se reconheçam como inseridos nesse perfil preconceituoso ao qual ele define a comunidade.

A questão da não valorização da comunidade é reafirmada na resposta dos pais, isso permite que os currículos continuem, naturalmente, a serviço de uma concepção de sociedade branca, elitizada e eurocêntrica. Nas palavras de Aníbal Quijano (2010):

O eurocentrismo não é exclusivamente, portanto, a perspectiva cognitiva dos europeus, ou apenas dos dominantes do capitalismo mundial, mas também do conjunto dos educados sob a sua hegemonia. E embora isso implique um componente etnocêntrico, este não o explica, nem é a sua fonte principal de sentido. Trata-se da perspectiva cognitiva durante o longo tempo do conjunto do mundo eurocentrado do capitalismo colonial/moderno e que naturaliza a experiência dos indivíduos neste padrão de poder. Ou seja, fá-las entender como naturais, consequentemente como dadas, não suscetíveis de ser questionadas (QUIJANO, 2010, p. 86).

Educados sob esta hegemonia, as instâncias de poder servem a um específico grupo da sociedade, esquecendo as classes historicamente inferiorizadas e naturalizando esse esquecimento, uma vez que consideram como algo dado, não sendo necessário transformá-lo.

O estudo acerca da história da comunidade não acontece, assim como essa história também não é trabalhada por meio do currículo escolar nas aulas, algo constatado quando perguntou-se aos professores: Você conhece a história da Comunidade Quilombola Negros do Riacho? Se sim, como faz para trabalhála? Obtendo como respostas:

Prof. 1: Olhe a gente não trabalha não. (Sic).

Prof. 2: Sim, um pouco a história oral. (Sic).

Se o conhecimento sobre a história da comunidade se dá em parte, e o prof. 2 não detalha como a história oral é trabalhada, o trabalho fica comprometido e, possivelmente, opta-se por trabalhar o que a historiografia e os livros didáticos trazem sobre negros, sobre quilombos e sobre escravidão, sob uma visão colonial. Ao relatar uma prática de (des)valorização da comunidade, o professor 2 nos conta, oralmente, sobre uma apresentação de expansão cultural preparada para os alunos da comunidade, na qual eles iriam se vestir de calças e sem camisa (vestimenta de escravizados) e entrar em um navio confeccionado para a encenação, aos moldes do navio negreiro.

$\mathrm{Na}$ fala do professor a atividade é mencionada como grandiosa por ser apresentada para toda a cidade ao mesmo tempo em que percebia um descontentamento do mesmo ao mencionar que "em cima da 
hora", um dia antes, os alunos da comunidade disseram que não participariam, participação que não foi conseguida, nem mediante o oferecimento de dois $(2,0)$ pontos de nota em avaliação na tentativa de persuadir os alunos a se apresentarem. Com a negação, a escola teve que trazer remanescentes de quilombolas de outra cidade do estado para desempenhar o papel. Essa prática escolar nos lança ao encontro do que diz Quijano:

A capacidade e a força que servem a um grupo para se imporem a outros, não são, no entanto, suficientes para articular histórias heterogéneas numa ordem estrutural duradoura. Elas certamente produzem autoridade enquanto capacidade de coerção. A força e a coerção ou, no olhar liberal, o consenso, não podem, contudo, produzir nem reproduzir duradouramente a ordem estrutural de uma sociedade, ou seja, as relações entre os próprios meios. Nem, em especial, produzir o sentido do movimento e do desenvolvimento históricos da estrutura societal no seu conjunto. A única coisa que pode fazer a autoridade é obrigar, ou persuadir, os indivíduos a submeter-se a essas relações e a esse sentido geral do movimento da sociedade que os habita. (QUIJANO, 2010, p. 92).

Representar escravos tripulantes dos navios negreiros revela uma prática didático-escolar de subalternização do povo negro, ao mesmo tempo em que demonstra que a escola ainda super valoriza a história do negro enquanto escravizado, ao invés de buscar trabalhar o empoderamento por meio das grandes contribuições deste povo para o país. Quando se perguntou se os alunos já haviam estudado no componente curricular História do Brasil a história da escravidão recebemos a resposta afirmativa, o que pode explicar a recusa dos meninos e meninas em participar da apresentação. Em contraponto à prática subalternizante nota-se a força do coletivo e a resistência dos estudantes quilombolas, aquilombando-se na negativa em participar de tão humilhante ação pedagógica.

Sobre a questão de sofrer preconceitos e receber apelidos na escola, todos os pais disseram que isso atualmente não acontece, mas alguns mencionaram que antes existia preconceitos pelo fato de serem alunos quilombolas. Resolvemos então indagar os professores sobre como ocorre a interação entre alunos quilombolas e os não quilombolas, se fazem trabalhos juntos, se sentam juntos e se compartilham as brincadeiras, obtendo como respostas:

Prof. 1: Olhe, eles brincam, mas não se misturam não, se amotinham, você sabe o que é se amotinhar? Pois pronto, se amotinham só eles. Tem as coisas aqui, os eventos, você pensa que eles vão? Não participam de nenhum. (Sic).

Prof. 3: Eles tem um senso de alta proteção coletiva, é tanto que se mexer com um, mexe com todos. (Sic).

Sob a voz dos professores percebe-se o não dito, todavia, explícito nas posturas dos estudantes. O fato de se "amotinharem" e não participar dos eventos e práticas alinhadas à colonialidade e branquitude revela a exclusão e distanciamento que lhes é imposto e assim, não se sentem à vontade em estarem em eventos e trabalhos acadêmicos que não lhes incluem tampouco os representam. Pelas respostas percebese mais uma vez, que a união ancestral da formação dos quilombos e até mesmo da vida nas senzalas antes necessária à sobrevivência se faz permanência na coletividade entre os atuais estudantes quilombolas, hoje, fortalecedora da identidade do grupo.

Percebe-se a necessidade e urgência de oferecimento de curso de formação continuada a esses professores sobre a Educação Escolar quilombola que aborde a formação dos quilombos, o quilombismo e os aquilombamentos. Esses estudantes não se "amotinhavam", mas sim, se aquilombavam. Aquilombamento aqui significa união, coletividade, senso de proteção e resistência: "se mexer com um, mexe com todos".

O preconceito aparece em outros moldes, em falas e atitudes de exclusão, muitas vezes de uma forma pouco perceptível para os pais. Na medida em que a escola desconsidera as tradições, não conhecem 
a história e não as trabalham nas práticas escolares, configura-se como processo de exclusão e negação dessa cultura.

A escola deve abordar e abarcar em seu Projeto Político Pedagógico (PPP) todas as culturas e os sujeitos que nela se inserem. No entanto, constatamos que a escola não possuía um PPP porque este se encontrava em fase de elaboração (ano de 2017).

Sabendo-se que os cursos de formação continuada constituem importante mecanismo de compreensão da história das comunidades tradicionais e povos subalternizados, convinha que se indagasse aos professores, o quanto lhes era oferecido essa possibilidade formativa. E, quando questionados se no município são ofertados cursos de formação continuada que enfatizem a Educação Escolar Quilombola e se os mesmos já participaram de algum desses cursos, estes nos responderam:

Prof.1: Curso de formação continuada? Tem não, mulher. Eu só sei de alguma coisa porque fiz minha especialização. (Sic).

Prof. 2: Às vezes sim. Já participei uma vez de uma palestra que não era sobre os quilombolas, mas era sobre respeitar culturas. (Sic).

Prof. 3: Não tem esses cursos não! (Sic)

Os cursos de formação continuada permitem aos professores o trabalho adequado com os materiais que versam sobre a Educação Escolar Quilombola, pois, sem estes cursos há uma maior tendência à reprodução da imagem subalternizada do povo negro, tal como costuma narrar a historiografia eurocêntrica. Do mesmo modo, sem a formação continuada, os professores podem ignorar o grupo étnico por não se considerar apto a trabalhar as questões que o envolvem tais como a religiosidade, as tradições, os costumes, a história e a cultura.

Com a pesquisa pudemos identificar que o trabalho desenvolvido na Escola Municipal P.H.G desconhece muito sobre a legislação e sobre a Comunidade Quilombola Negros do Riacho, o que inviabiliza ações de valorização da cultura desse povo remanescente. Percebeu-se que, mesmo não explicitamente, ainda vigora o preconceito e a discriminação, na medida em que a escola deixa em segundo plano as pessoas da comunidade, seja para diálogo, seja para participação nos eventos. Quando é dada a oportunidade de participação, esta ocorre de forma equivocada seguindo o modelo de representação dos negros difundido na sociedade herdeira da Casa Grande e Senzala, a do escravo que levou sua vida a servir de mercadoria para uma elite hegemonicamente branca e economicamente superior.

O capitalismo, a colonialidade, os resquícios do colonialismo, o eurocentrismo e o pensamento abissal, conceitos trazidos à tona neste estudo estão presentes nas ações da escola ao mesmo tempo em operam a subalternização na vida dos estudantes quilombolas. E a mudança desse status quo requer muito esforço e formação adequada para se compreender as lutas da população negra enquanto raça interseccionada à classe social hierarquicamente inferiorizada pelo racismo que estrutura a sociedade Brasileira (ALMEIDA, 2019), ou seja, se antes o povo negro era dominado pelos poderosos donos de terras, tendo sua vida restrita ao trabalho escravo, hoje ele é submisso ao padrão de poder, às estruturas e às instituições sociais, estando ainda em um processo de libertação inacabada.

\section{Considerações Finais}

Este estudo teve como objetivo conhecer melhor como se dá a educação de estudantes quilombolas provenientes de uma Comunidade quilombola do interior do rio Grande do Norte, conhecida como Negros do Riacho, matriculados em uma escola urbana. A pesquisa visou responder à seguinte problemática: Na visão dos pais e mães de alunos quilombolas, as práticas escolares da Escola Municipal Professor Humberto Gama têm contribuído para a valorização da identidade, tradições e costumes da Comunidade Quilombola Negros do Riacho? 
Em busca de respostas centramos o estudo se ancorou nas políticas de ações afirmativas e seus marcos regulatórios, bem como em autores que tratam da temática na busca por subsídios para responder a problemática em questão e, nos questionários aplicados aos professores e entrevistas feitas aos pais e mães dos e das estudantes. O conhecimento da história da escravidão e da formação dos quilombos no Brasil fez-se importante para que se entendesse o passado marcado pelo sofrimento, exclusão, mas também o processo de lutas e resistências travadas pela população negra brasileira em busca da liberdade. A consciência desse processo aliado à luta dos movimentos sociais negros fez emergir políticas públicas de ações afirmativas e legislações que introduziram a recuperação de direitos em prol da dignidade dos descendentes da diáspora africana.

Os quilombos dos Séculos XVI a XIX nos remetem à ideia de resistência histórica e como herança dessa formação temos hoje as comunidades tradicionais remanescentes de quilombolas, espaços de manutenção das tradições, memória e valores ancestrais sendo esses espaços que mantêm viva a luta pela igualdade, a busca e a garantia de direitos. A escola se constitui em espaço fundamental para com a valorização dos remanescentes de quilombolas, implementar as ações afirmativas e executar as orientações provenientes das legislações.

O estudo realizado com pais e mães de alunos que estudam na Escola Municipal P.H.G, município de Currais Novos e com os professores desses estudantes demonstraram que as práticas escolares não trabalham a história, nem a memória, tampouco os valores da comunidade Negros do Riacho. As evidências, apontam para o pouco conhecimento que os profissionais possuem acerca da comunidade e de seu território, sua história, tradições e costumes, o que acarreta, socialmente falando, a desvalorização desses alunos quilombolas ao mesmo tempo que dificulta-lhes o processo de construção e ou reconhecimento de suas identidades, negando aos jovens o direito à educação escolar quilombola conforme os princípios da Resolução ${ }^{\circ}$ 08/2012.

Também pudemos identificar nos discursos relativos às práticas escolares a presença do eurocentrismo, que segue como modelo a Europa e tudo que dela deriva, excluindo o que não se encontra dentro deste padrão hegemônico. Este fenômeno se instalou na sociedade com o capitalismo e a globalização e ganhou força adquirindo seguidores que, não necessariamente são europeus, mas que vêem nessa cultura e nesses povos a forma ideal de sociedade e, portanto, buscam incorporá-la.

O estudo salientou também que os descendentes da diáspora africana -, que antes sofriam o peso do fenômeno do colonialismo caracterizado pela dominação/exploração de um povo sobre outro e do controle/autoridade exercido sobre seus territórios -, hoje se tornam vítimas do fenômeno da colonialidade, posto que a colonialidade, mais duradoura que o colonialismo e derivante deste, envolve em seu seio questões raciais e hierarquiza a sociedade em classes sociais, de modo que uma classe exerce poder sobre outra na medida em que detém capital (econômico, cultural, epistemológico). A colonialidade é elemento fundante do padrão de poder capitalista mundialmente dominante e tornou-se hegemônico na sociedade.

Diante destas considerações, espera-se que o resultado desta pesquisa possa fazer com que os profissionais das instituições responsáveis pelo ensino nos âmbitos estadual, municipal e federal incorporem em suas práticas as políticas de ações afirmativas e assim possam oferecer cursos de formação continuada de curta ou média duração, cursos em nível de pós-gradução (Lato e Stricto Senso) aos professores para que se viabilizem as possibilidades de transformação das práticas e currículos escolares, com vistas a que estudantes negros, quilombolas e das demais etnias se vejam representados na escola em que estudam sem o temor da exclusão e do racismo estrutural que ainda permeia tantas instituições escolares. 


\section{REFERÊNCIAS}

AIRES, Ana Maria Pereira; GARCIA, Maria de Fátima. A Educação Escolar Quilombola No Processo de Construção do PPP da Escola Municipal São Francisco de Assis: Os Sentidos dos Sujeitos. In: MOREIRA Antônio Flavio B.; FERNANDES Claudia; et al (Org.). Didática(S) Entre Diálogos, Insurgências E Políticas: Tensões e Perspectivas na Relação com Currículo e Avaliação - LIVRO 2. 1ed. Petrópolis - RJ: Faperj; CNPq; Capes; Endipe, 2020, v. 1, p. 1807-1817.

AIRES, Ana Maria Pereira; LEITE, Joana. A. S. Educação escolar quilombola: ausências e intencionalidades no processo de construção do projeto político-pedagógico. In: GARCIA Maria de Fátima; SILVA, José Antonio Novaes da. (Org.). Africanidades, Afrobrasilidades e Processo (Des)Colonizador: Contribuições à Implementação da Lei 10.639/03. 1ed. Editora UFPB, v. 1, p. 114-153. João Pessoa: 2018

ALMEIDA, Silvio Luiz de. Racismo Estrutural. São Paulo: Pólen, 2019. 264 p. (Feminismos Plurais / coordenação de Djamila Ribeiro). ISBN: 978-85-98349-74-9

BARROS, José D’Assunção. A. A Construção Social da Cor. Diferença e desigualdade na formação da sociedade brasileira. Petrópolis: Vozes, 2009.

BRASIL. Educação para as Relações Étnico-Raciais/ Educação Escolar Quilombola acessível em:

http://etnicoracial.mec.gov.br/educacao-escolar-quilombola. Acesso em 17/08/2021.

BEVERLEY, John. Tesis about subalternidad, representación y política. In: OLIVEIRA, Marynize Prates de; PEREIRA, Maurício Matos dos Santos; CARRASCOSA, Denise (Org.). Cartografias da subalternidade: diálogos no eixo sul-sul. Salvador: EDUFBA, 2014.

BRASIL. Ministério da Educação. Diretrizes Curriculares Nacionais da Educação Básica. MEC/SEB, 2013.

. Ministério da Educação. Conselho Nacional de Educação. Câmara de Educação Básica. Parecer CNE/CEB no 16/2012 e Resolução CNE/CEB no 8/2012. In: Diretrizes Curriculares Nacionais da Educação Básica: MEC/SEB, 2013.

. Presidência da República. Constituição da República Federativa do Brasil de 1988. Disponível em: <http://www.planalto.gov.br/ccivil_03/constituicao/constituicaocompilado.htm>. Acesso em: 20 fev. 2017.

Presidência da República. Lei $n^{\mathbf{0}}$ 10.639, de 09 de Janeiro de 2013. Disponível em: <http://www.planalto.gov.br/ccivil_03/leis/2003/L10.639.htm>. Acesso em: $11 \mathrm{dez} .2016$.

GARCIA, Maria de Fátima; DANTAS, Ana Ionara. A Fotografia Revelada pela Lente dos/das Adolescentes Quilombolas: Cultura, Identidade e Gênero. In: GARCIA, Maria de Fátima; SILVA, José Antonio N. da. (Org.). Africanidades, Afrobrasilidades e Processo (Des)Colonizador: Contribuições à Implementação da Lei 10.639/03. 1ed. , v. 1, p. 155-199. João Pessoa: UFPB, 2018.

GERHARDT, Tatiana Engel; SILVEIRA, Denise Tolfo (orgs). Métodos de Pesquisa. Porto Alegre: Editora da UFRGS, 2009.

KILOMBA, Grada. Memórias da Plantação: Episódios de Racismo Cotidiano. Cobogó: 2008.

LUDKE, Menga; ANDRÉ, Marli. Pesquisa qualitativa em educação. São Paulo: EPU, 2003.

NASCIMENTO, Abdias. O Quilombismo: Documentos de uma militância Pan-Africanista. $3^{\text {a }}$. Edição revista. São Paulo: Perspectiva, 2019 (não paginado).

REIS, João José; GOMES, Flávio dos Santos. (Org.). Liberdade por um fio: História dos Quilombos no Brasil. São Paulo: Companhia das Letras, 1996. 
SANTOS, José Antonio. Diáspora africana: Paraíso perdido ou terra prometida. In: MACEDO, JR. (Org) Desvendando a História da África. Porto Alegre: Editora da UFRGS, 2008. Diversidades séries, pp. 181194. ISBN 978-85-386-0383-2. Available from: doi: 10.7476/9788538603832. Alsoavailable in ePUB from: http://books.scielo.org/id/yf4cf/epub/macedo-9788538603832.epub

SANTOS, Boaventura de Sousa; Para além do Pensamento Abissal: Das linhas globais a uma ecologia de saberes. In: SANTOS, Boaventura de Sousa; MENEZES, Maria Paula. (Org.). Epistemologias do Sul. São Paulo: Cortez, 2010.

QUIJANO, ANIBAL. Colonialidade do poder e classificação social. In: SANTOS, Boaventura de Sousa; MENEZES, Maria Paula. (Org.) Epistemologias do Sul. São Paulo: Cortez, 2010. 